\title{
How Can New Building Materials Play the Role of Energy Conservation and Environmental Protection
}

\author{
Haozheng Wang ${ }^{1}$ \\ ${ }^{1}$ Xi'an Gaoxin No.1 High School, Chang'an District, Xi'an, Shaanxi province \\ *843194756@qq.com
}

\begin{abstract}
In recent years, with the severity of the world energy crisis, new building energy-saving materials came into being. The emergence of new building materials has brought a new situation to the whole construction industry and played a positive role in promoting the construction industry. With the price advantage of new building materials, remarkable progress has been made in improving housing construction capacity, optimizing operation process, improving effective utilization of resources, reducing toxic and harmful substance emissions, and realizing the concept of world environmental protection action. The role of new materials in energy conservation and environmental protection is expanding, and the domestic construction industry has made great progress in sustainable development. In the future, the construction industry needs to gradually develop the use ability of new materials, standardize the raw material market and show the powerful power of modern science and technology.
\end{abstract}

Keywords: New Building Material; Energy Conservation ; Environmental Protection;

\section{INTRODUCTION}

According to statistics, China's construction industry is developing at an average annual rate of 2 billion square meters. On the other hand, building energy consumption accounts for $27.5 \%$ of the final energy consumption of the whole society. Building energy conservation is mainly to improve walls[1], windows and roofs, improve heat insulation and sealing, and reduce the energy consumption of heating, air conditioning and other facilities, so as to improve the living environment and save energy. When it comes to building energy conservation, it is closely related to building materials[2]. At present, China's new building energy-saving materials are far behind developed countries in product structure, overall engineering level and product quality, which is related to energy-saving effect. New building materials are different from traditional building materials[3]. In terms of materials, there are not only natural materials, but also chemical materials, metal materials, non-metallic materials, etc. Alberto Vilches' researchs[4]predict that in Europe, in 2050 to $80 \%$ of all buildings is one of the existing buildings, so the renovation of existing buildings, in order to reduce its impact on the environment and climate change mitigation is of great significance. In China, people are discussing how to improve building energy efficiency and reduce the "greenhouse effect" of carbon dioxide.

\section{CONCEPT OF NEW ENERGY-SAVING AND ENVIRONMENTAL PROTECTION BUILDING MATERIALS}

New environmental protection building raw materials are not polluted by the natural environment, and it's non-radioactive and do not produce radiation. At the same time, it can avoid the harm to human body caused by excessive harmful substances released by building materials. In addition to the provisions of energy conservation and environmental protection, the main function of new energy-saving and emission reduction building materials is to improve the thermal insulation capacity. New building materials can avoid the resource loss caused by HVAC to the greatest extent and achieve the effect of energy conservation and environmental protection. Therefore, we should strengthen the application of new energy-saving and environmental protection materials in residential construction projects, pay attention to the concept of energy conservation and emission reduction, and promote resource conservation and sustainable development. It can be seen that the application and research and development of new energy-saving and 
environmental protection building materials are of great significance to improve people's quality of life and promote social development.

\section{CONCEPT OF BUILDING ENERGY CONSERVATION AND ENVIRONMENTAL PROTECTION}

Building energy conservation is the need of social development and helps to alleviate the problem of energy shortage. Building energy conservation is the need of environmental protection, which helps to reduce the current air pollution. Building energy conservation means that in the process of building planning and design, new materials and technologies are adopted to reasonably design the thermal performance of building protective structure, heating, lighting, ventilation, water supply and operation efficiency of pipeline system. The production, construction engineering and use of building materials can reduce energy consumption. At the same time, it will be reasonable and scientific, making efficient use of energy, improving the comfort of buildings and achieving the purpose of energy saving. In short, it is to consume as little energy as possible and let people live a comfortable life as much as possible.

\section{SPECIFIC APPLICATION OF NEW BUILDING MATERIALS IN ENERGY CONSERVATION AND ENVIRONMENTAL PROTECTION IN CONSTRUCTION ENGINEERING}

\subsection{Wall Insulation of Buildings}

Nowadays, science and technology are developing rapidly. People's requirements for residential architectural design are more and more novel and strict. It should not only meet the functional needs of residential buildings, but also actively integrate the design of ecological and environmental protection concept. The market of new building materials is relatively complex, and the types of building materials are also diverse. In the wall insulation design, many house builders have conducted a comprehensive investigation and research on the building materials market, and divided the materials with cost performance as the first consideration factor. Now, the thermal insulation design of the wall is generally to make a partition wall on the wall of the house, and implement the work of thermal insulation partition wall in combination with composite raw materials. The whole workflow has low complexity and remarkable effect, and has been widely used in engineering projects. In addition, there are significant regional climate differences in China, especially the low temperature in winter in many parts of the north. Setting thermal insulation partition wall in the house wall to improve the cold resistance of the house building, and adding thermal insulation building materials outside the wall can effectively improve the utilization efficiency of the external space of the house building. In addition, the maintenance of thermal insulation exterior wall has little impact on work and life.
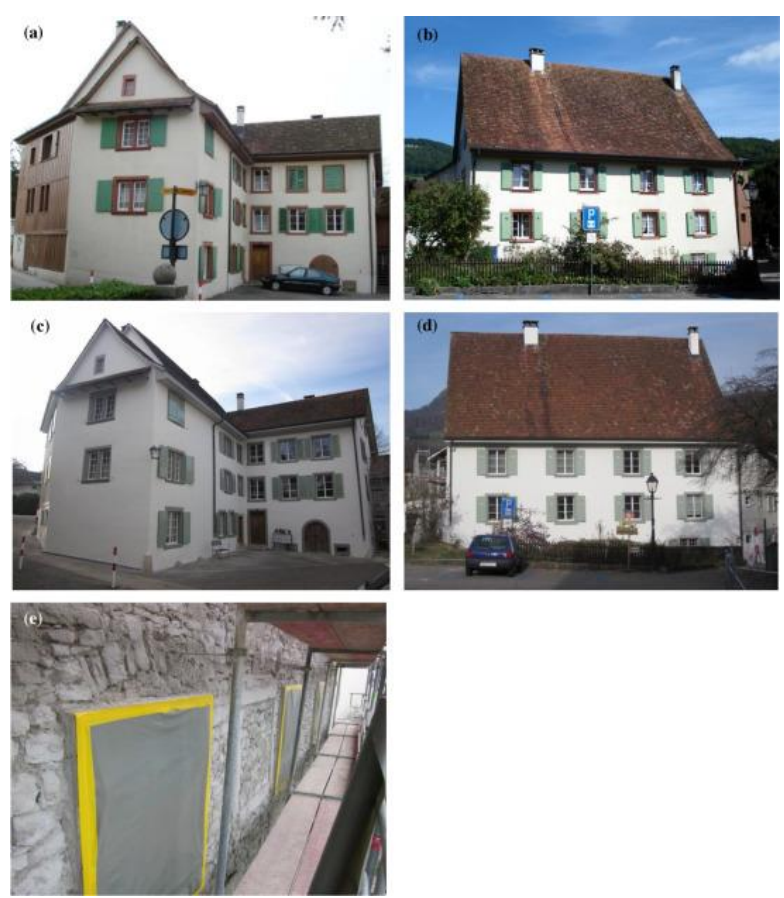

Fig.1. The old mill in Sissach from the 13th century.

Before refurbishment (a, b), and afterwards (c, d).

Renovation of the façade of the mill: (e) the existing, non-historical render removed, (f) aerogel render is applied on the lime quarry.

Aerogel is a new material with high porosity, low density and high thermal insulation performance. Old buildings usually have poor thermal insulation, resulting in high energy consumption And Europe has many old buildings because of its long history. Michal Ganobjak[5]reviewed the application of commercial aerogel in conservation and restoration of heritage buildings and in reducing energy consumption and carbon dioxide. Taking an old mill in Switzerland (Fig 1) as an example, aerogel replaced the existing render, with an average thickness of $50 \mathrm{~mm}$ and coverage area of about $440 \mathrm{~m}^{2}$ and other measures, the energy consumption of the building was reduced by about $60 \%$.

\subsection{New Energy-saving and Environmental Protection Building Doors and Windows}

There are strict requirements for building structure. In addition to the treatment and analysis of large-area working walls, it is also necessary to scientifically and reasonably plan the proportion of doors and windows to ensure the user's sense of use. In the process of door and window design, relevant personnel must better control the indoor ventilation, heat insulation and daylighting, 
and use materials reasonably. This can effectively adjust the internal temperature of the room and ensure that the new doors and windows will bring users a more comfortable experience. In order to better solve the problem of door frame loss in traditional residential design, it is necessary to adopt energy-saving and environmentally friendly doors and windows to fundamentally control the hidden dangers of door and window use quality. Many doors and windows are made of insulating glass. It has been updated and utilized in the process of urban construction and planning, and it has good daylighting performance. At the same time, its sealing performance is also very good, which can avoid the loss of indoor heat energy to the greatest extent.

\subsection{Application of Energy-saving Roof}

Thermal insulation materials with low bulk density, low thermal conductivity, low water absorption and certain strength are generally set between the waterproof layer and the roof panel. According to this forward laying method, a variety of thermal insulation materials can be selected, including aerated concrete blocks, cement or asphalt perlite plates, cement polystyrene plates, polystyrene plates and various lightweight aggregate concrete plates. On site pouring perlite, pumice, slag and son on. There are also glass wool and waste polystyrene, which are directly or bagged under the loose roof or ceiling. Foamed concrete was foamed on the spot with rigid polychlorinated foam plastics, fly ash and cement as main materials. The reverse paving method mainly places the waterproof layer under the thermal insulation layer, which can effectively protect the waterproof layer and facilitate construction and maintenance. However, due to the high cost, residential buildings and residential buildings haven't been widely used.

Table1 Comparison of annual efficacy of a PCT of 25 ${ }^{\circ} \mathrm{C}$ or $29^{\circ} \mathrm{C}$ in Taipei.

\begin{tabular}{cccc}
\hline PCT $\left({ }^{\circ} \mathrm{C}\right)$ & 25 & 29 & Difference \\
\hline $\begin{array}{c}\text { Overheating Hours, I1 } \\
\text { (hr) }\end{array}$ & 80 & 51 & 29 \\
Weighted & & & \\
Overheating Hours, I2 \\
(hr) & 206 & 184 & 22 \\
Energy-Saving & 2.5 & 4.7 & -2.2 \\
Potential (GJ) & $(3.7 \%)$ & $(6.9 \%)$ & $(-3.2 \%)$ \\
\hline
\end{tabular}

Phase Change Materials (PCM) have a large heat capacity over a limited temperature range, similar to isothermal storage tanks, and are considered to be an innovative technology and an effective method to improve the thermal quality of buildings. Ruey-Lung
Hwang's selection of school buildings in Taipei and Kaohsiung as target buildings confirms the benefits of roof structure combined with PCM[6]for building energy efficiency (Table1).

\subsection{Building Envelope}

In the residential construction project, in addition to the wall and door frame, the protective structure design of residential buildings will also adopt new energysaving and environmental protection building materials. In practical work, the protection structure of the house is technically very complex, and the problems considered are also very diverse. It not only has the corresponding protection ability of the house, but also considers the factors such as the internal ambient temperature and external pressure of the house. Therefore, when applying energy-saving materials, the function of protective structure must be fully combined. Bricks are usually used to ensure the stability of buildings when carrying out works.

\section{PROMOTION MEASURES OF NEW ENERGY-SAVING AND ENVIRONMENTAL PROTECTION BUILDING MATERIALS}

\subsection{Standardize the Material Market and Enhance the Management Ability}

At present, the domestic traditional housing construction raw material market is relatively stable, with extremely mature operation plan and detailed and comprehensive planning method. In recent years, the market of new energy-saving and environmental protection building materials has shown a high fever, but due to the immature market, there is a lack of guidance of the standard system. The mixed situation of building materials enterprises has emerged. Some enterprises take environmental protection buildings as signboards to obtain illegal interests, which directly affects the construction quality. In view of this situation, China should formulate market norms and production requirements norms according to the characteristics of new building materials to prevent inferior products and building materials from entering into the market.

\subsection{Enhance the Research Strength of New Materials and Innovate Synthesis Technology}

At present, new energy-saving and environmentfriendly residential building materials can meet the basic requirements of residential buildings. However, the climate and geographical conditions of many housing construction workplaces are complex, and the construction regulations of housing construction are relatively strict. New energy-saving and environment- 
friendly building materials need to be further improved and developed. Start the laboratory construction, improve the professional ability of the R \&amp; D team, learn to introduce foreign advanced technology, innovate thinking, develop new energy-saving and environmental protection materials suitable for Chinese housing construction projects, and conduct practical evaluation and effective control of new materials in the process of basic engineering from the perspective of onsite operation.

\subsection{Vigorously Advocate the Concept of Environmental Protection to Make it Deeply Rooted in the Hearts of People}

Now, environmental protection actions have spread all over the world. In order to promote environmental protection and the establishment of social order, China needs to vigorously advocate the concept of natural ecological environmental protection and deeply rooted energy conservation and environmental protection in the hearts of the people. During construction, managers and operators participate in the cultivation of environmental protection concept, improve the utilization efficiency of environmental protection raw materials of operators, strengthen the use of new building materials, carry out energy-saving control in many aspects of construction, significantly improve the building quality, integrate environmental protection concept into material utilization, and promote the recycling of building materials.

\subsection{Other Energy-saving Applications}

Solar energy is a common renewable energy for buildings. It is rich in resources and can be used free of charge.

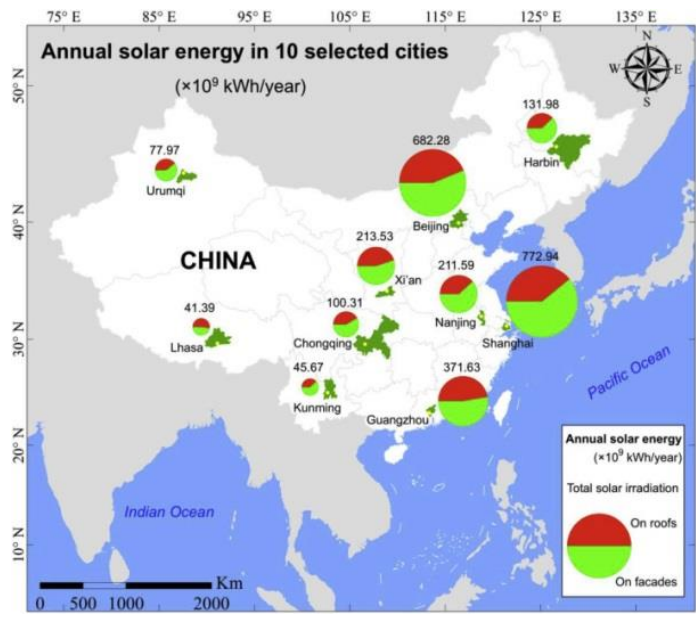

Fig. 2. Annual solar irradiation received by building envelops in 10 selected cities.

No transportation is required and there is no pollution to the environment. Solar energy and buildings provide us with a renewable way to make effective use of resources. When using solar energy, solar energy devices and buildings should be organically combined. Liang Cheng's results show that the actual potential of solar energy in cities outside Lhasa is expected to more than double every year because of the presence of building facades (green). As shown in Figure 2[7], solar irradiation is represented by stacked bars. The annual solar potential of the 10 cities ranged from 41.39 (Lhasa) to 772.94 TWh (Shanghai).

\section{CONCLUSION}

The use of new energy-saving and environmental protection building materials reduces the pollution of building materials and improves the overall energy conservation and emission reduction effect of buildings. The wall energy-saving and thermal insulation technology and the energy-saving and emission reduction design of composite glass structure are organically combined with the building to effectively improve the comfort of the internal environment of the house and the environmental protection performance of the building, so as to achieve the ultimate goal of energy conservation and environmental protection.

\section{REFERENCES}

[1] Li Shaonao. On Energy-saving and Environmental Protection Performance of New Building Materials [J].Information Recording Materials,2020,21(09):16-17.

[2] Li Haipei, Xu Qi. Application of New Building Materials in Civil Engineering [J].Anhui Aichitecture,2020,27(08)

[3] Wang Xinbo. Application of Energy-saving and Environmental Protection Technology in Civil Engineering Construction [J].Jushe,2019(23):43..

[4] Vilches, A., Garcia-Martinez, A. \& SanchezMontañes, B. Life cycle assessment (LCA) of building refurbishment: A literature review. [J] Energy Build. 135, 286-301 (2017).

[5] Ganobjak, M., Brunner, S. \& Wernery, J. Aerogel materials for heritage buildings: Materials, properties and case studies. [J] Journal of Cultural Heritage. 42, 81-98 (2020).

[6] Hwang, R. L., Chen, B. L. \& Chen, W. A. Analysis of incorporating a phase change material in a roof for the thermal management of school buildings in hot-humid climates. [J] Buildings 11, (2021).

[7] Cheng, L. et al. Solar energy potential of urban buildings in 10 cities of China. [J] Energy 196, 117038 (2020). 